\title{
Effects of $\mathrm{Li}^{+}$Codoping on the Optical Properties of $\mathrm{SrAl}_{2} \mathrm{O}_{4}$ Long Afterglow Ceramic Phosphors
}

\author{
Timur Sh. Atabaev, ${ }^{1}$ Hong Ha Thi Vu, ${ }^{1}$ Mac Kim, ${ }^{2}$ Yong Suk Yang, \\ Hyung-Kook Kim, ${ }^{1}$ and Yoon-Hwae Hwang ${ }^{1}$ \\ ${ }^{1}$ Department of Nanomaterials Engineering, Pusan National University, Miryang 627-706, Republic of Korea \\ ${ }^{2}$ Department of Nano Fusion Technology, Pusan National University, Busan 609-735, Republic of Korea
}

Correspondence should be addressed to Hyung-Kook Kim; hkkim@pusan.ac.kr and Yoon-Hwae Hwang; yhwang@pusan.ac.kr

Received 1 April 2014; Accepted 15 July 2014; Published 4 August 2014

Academic Editor: Marco Consales

Copyright (C) 2014 Timur Sh. Atabaev et al. This is an open access article distributed under the Creative Commons Attribution License, which permits unrestricted use, distribution, and reproduction in any medium, provided the original work is properly cited.

\begin{abstract}
Rare-earths codoped long afterglow strontium aluminate phosphors with high brightness were synthesized via a facile combustion synthesis method using urea as a fuel. The resulted phosphor particles were analyzed by using X-ray diffraction and field emission scanning electron microscope, whereas their optical properties were monitored by photoluminescence spectroscopy. The prepared $\mathrm{SrAl}_{2} \mathrm{O}_{4}: \mathrm{Eu}^{2+}, \mathrm{Dy}^{3+}, \mathrm{Li}^{+}$samples showed a broad green-yellowish emission, peaking at $512 \mathrm{~nm}$ when excited by $348 \mathrm{~nm}$. Compared to traditional $\mathrm{SrAl}_{2} \mathrm{O}_{4}: \mathrm{Eu}^{2+}, \mathrm{Dy}^{3+}$ phosphor, the initial luminescence brightness of $\mathrm{SrAl}_{2} \mathrm{O}_{4}: \mathrm{Eu}^{2+}, \mathrm{Dy}^{3+}$, codoped with $\mathrm{Li}^{+}$improved from $1.89 \mathrm{~cd} / \mathrm{m}^{2}$ to $2.71 \mathrm{~cd} / \mathrm{m}^{2}$ and the afterglow decay time was prolonged from 103 to $121 \mathrm{~min}$. The possible mechanism of $\mathrm{SrAl}_{2} \mathrm{O}_{4}: \mathrm{Eu}^{2+}, \mathrm{Dy}^{3+}, \mathrm{Li}^{+}$phosphorescence enhancement has been discussed.
\end{abstract}

\section{Introduction}

Long afterglow phosphor is a kind of energy-storing material, which can absorb the light photons, store the energy, and then release the energy as visible light. Alkaline aluminates based phosphor materials generally generate more defect-related traps when they are doped with rare-earths $\mathrm{RE}$. The luminescence emission of these RE-doped alkaline aluminates is strongly dependent on the host lattice and can occur from the ultraviolet to the red region. For example, $\mathrm{CaAl}_{4} \mathrm{O}_{7}: \mathrm{Eu}^{2+}, \mathrm{Dy}^{3+}$ phosphors exhibited a broad blue emission band with the main peak at $445 \mathrm{~nm}$ [1]. The emission colour of $\mathrm{MgAl}_{4} \mathrm{O}_{7}: \mathrm{Eu}^{2+}$, $\mathrm{Dy}^{3+}$ nanoparticles shifts from bluish $\left(700^{\circ} \mathrm{C}\right)$ to reddish $\left(900^{\circ} \mathrm{C}\right)$ with increasing calcination temperature [2]. Recently, strontium aluminates activated with rare-earths have attracted a lot of attention since they exhibit excellent properties such as long afterglow time, high quantum efficiency, good phase stability, and bright emitting color [3], when compared with known sulfide long afterglow phosphors. Since the lifetime greatly exceeds that of any other material, this offers an unexpectedly large field of applications for the use of these aluminates $[4,5]$.

Although many studies have examined the optical properties of RE-doped alkaline aluminates, only a few have investigated the codoping of three or more different ions in the same host material. It is also known that optical properties of phosphorescent materials are strongly influenced by the incorporation of auxiliary activators. Among them, smaller cationic radius of $\mathrm{Li}^{+}$ions are favored for their movement and site occupation in the host matrix and these advantages make them attractive for tailoring the crystal field of host lattice [6]. There are many reports on significant enhancement in emission intensity with $\mathrm{Li}^{+}$codoping in different hosts $[7,8]$. To the best of our knowledge, there is no report on improvement of green phosphorescence with $\mathrm{Li}^{+}$ion incorporation in $\mathrm{SrAl}_{2} \mathrm{O}_{4}: \mathrm{Eu}^{2+}, \mathrm{Dy}^{3+}$ phosphors.

Herein, we report the synthesis of $\mathrm{Li}^{+}$-tailored $\mathrm{SrAl}_{2} \mathrm{O}_{4}: \mathrm{Eu}^{2+}, \mathrm{Dy}^{3+}$ prepared by combustion method, which shows better luminescent properties than the bare $\mathrm{SrAl}_{2} \mathrm{O}_{4}: \mathrm{Eu}^{2+}, \mathrm{Dy}^{3+}$ phosphor. The optimal synthesis 
conditions were researched systematically. The optical characteristics were investigated by analyzing the normalized room-temperature emission spectra. Codoping $\mathrm{Li}^{+}$into $\mathrm{SrAl}_{2} \mathrm{O}_{4}: \mathrm{Eu}^{2+}, \mathrm{Dy}^{3+}$ could enhance the emission intensity of $\mathrm{SrAl}_{2} \mathrm{O}_{4}: \mathrm{Eu}^{2+}, \mathrm{Dy}^{3+}$, and the emission intensity of $\mathrm{SrAl}_{2} \mathrm{O}_{4}: \mathrm{Eu}^{2+}, \mathrm{Dy}^{3+}$ varied with the $\mathrm{Li}^{+}$concentration. Thus, the present study was set up to investigate the influence of $\mathrm{Li}^{+}$concentration on the emission spectra and discuss the mechanism of the enhanced phosphorescence.

\section{Experimental}

2.1. Fabrication. High purity $\mathrm{Sr}\left(\mathrm{NO}_{3}\right)_{2}, \mathrm{Al}\left(\mathrm{NO}_{3}\right)_{3} \cdot 9 \mathrm{H}_{2} \mathrm{O}$, $\mathrm{Eu}\left(\mathrm{NO}_{3}\right)_{3} \cdot 5 \mathrm{H}_{2} \mathrm{O}, \mathrm{Dy}\left(\mathrm{NO}_{3}\right)_{3} \cdot 5 \mathrm{H}_{2} \mathrm{O}, \mathrm{LiNO}_{3}$, and $\mathrm{CO}\left(\mathrm{NH}_{2}\right)_{2}$ were purchased from Sigma-Aldrich and used as received. In a typical synthesis method, $\mathrm{Sr}\left(\mathrm{NO}_{3}\right)_{2}, \mathrm{Al}\left(\mathrm{NO}_{3}\right)_{3} \cdot 9 \mathrm{H}_{2} \mathrm{O}$, $\mathrm{Eu}\left(\mathrm{NO}_{3}\right)_{3} \cdot 5 \mathrm{H}_{2} \mathrm{O}, \mathrm{Dy}\left(\mathrm{NO}_{3}\right)_{3} \cdot 5 \mathrm{H}_{2} \mathrm{O}$, and $\mathrm{LiNO}_{3}$ were dissolved in a minimum amount of deionized DI water at a molar ratio of $1: 2: 0.03: 0.03: \mathrm{X}(0 \leq X \leq 0.05)$, respectively. Second, $5 \mathrm{~g}$ of urea was added to each sample. After mixing, the samples were introduced into a muffle furnace and then heated to about $300^{\circ} \mathrm{C}$ for $1 \mathrm{~h}$, where the organic fuels and metal nitrates were automatically ignited and reacted to burn. Finally, the samples were precalcinated at $800^{\circ} \mathrm{C}$ in air atmosphere for $2 \mathrm{~h}$ to remove residual carbon and subsequently calcined at $1200^{\circ} \mathrm{C}$ under $1 \times 10^{-4}$ Torr vacuum for $3 \mathrm{~h}$.

2.2. Characterization. The structure of the prepared powders was examined by XRD using a Bruker D8 discover diffractometer (Bruker Optics Inc., MA, USA) with $\mathrm{Cu} \mathrm{K} \alpha$ radiation $(\lambda=0.15405 \mathrm{~nm})$ and a $2 \theta$ scan range of 20 to $60^{\circ}$. The morphologies of the particles were characterized by FESEM (Hitachi S-4700, Hitachi, Ltd., Tokyo, Japan). Elemental analysis was carried out by energy dispersive X-ray spectroscopy (EDX, Horiba. 6853-H). The PL measurements were measured by placing the powders to standard powder holder on a Hitachi F-7000 (Hitachi, Ltd., Tokyo, Japan) spectrophotometer equipped with a 150-W xenon lamp as an excitation source. All the measurements were performed at room temperature.

\section{Results and Discussion}

FESEM study was carried out to investigate the surface morphology and the crystallite sizes of the synthesized powders. Figure 1(a) shows the representative FESEM image of the bare $\mathrm{SrAl}_{2} \mathrm{O}_{4}: \mathrm{Eu}^{2+}, \mathrm{Dy}^{3+}$ powder. From the FESEM image, it is apparent that the crystallite sizes of the bare $\mathrm{SrAl}_{2} \mathrm{O}_{4}: \mathrm{Eu}^{2+}, \mathrm{Dy}^{3+}$ powder vary from nanometer range to several tens of microns. It was observed that the crystallite sizes are nearly the same for all compositions prepared (not shown for other samples). The EDX analysis of $\mathrm{SrAl}_{2} \mathrm{O}_{4}: \mathrm{Eu}^{2+}$, $\mathrm{Dy}^{3+}$ powder confirmed the presence of europium and dysprosium elements in the $\mathrm{SrAl}_{2} \mathrm{O}_{4}$ host matrix as shown in Figure 1(b).

All the samples were further examined by PL at room temperature under $348 \mathrm{~nm}$ excitation to examine the effects of $\mathrm{Li}^{+}$concentration on the phosphorescent properties of the synthesized samples. Figure 2 shows the normalized PL excitation and emission spectra of the samples measured in the range of 200-700 nm. PL excitation spectra of $\mathrm{SrAl}_{2} \mathrm{O}_{4}: \mathrm{Eu}^{2+}, \mathrm{Dy}^{3+}$ codoped with $0.03 \mathrm{~mol} \%$ of $\mathrm{Li}^{+}$(black line) shows a strong broad absorption with a maximum at $348 \mathrm{~nm}\left(4 \mathrm{f}^{7}\left({ }^{8} \mathrm{~S}_{7 / 2}\right) \rightarrow 4 \mathrm{f}^{6} 5 \mathrm{~d}\right.$ transition $)$ in the ultraviolet UV region. All the samples emit green-yellowish light with a very broad band centered at $512 \mathrm{~nm}$ when they were excited by the $348 \mathrm{~nm}$ UV light, which can be identified as the $4 \mathrm{f}^{6} 5 \mathrm{~d}^{1} \rightarrow 4 \mathrm{f}^{7}$ electric dipole-allowed transition of $\mathrm{Eu}^{2+}$ [3]. The shapes and position of the bands remain the same irrespective to the $\mathrm{Li}^{+}$content, whereas the intensity varies with $\mathrm{Li}^{+}$concentration. The normalized emission intensity of the samples linearly increases with increased $\mathrm{Li}^{+}$content and reached a maximum when the concentration was $0.03 \mathrm{~mol} \%$ and then decreased at higher concentrations.

Owing to its small size, $\mathrm{Li}^{+}$ions, when codoped into $\mathrm{SrAl}_{2} \mathrm{O}_{4}: \mathrm{Eu}^{2+}, \mathrm{Dy}^{3+}$, can diffuse to various interstitial sites in the host lattice. Thus the banned transitions can become allowed for $\mathrm{Li}^{+}$-tailored phosphors, since the inversion symmetry can be easily destroyed by the interstitial $\mathrm{Li}^{+}$ions in the host matrix [9]. Therefore, the distortion of the local symmetry in the host matrix favors to enhanced phosphorescent emission. However, the enhanced phosphorescent emission can be also associated with a better crystallinity of the final composites, leading to fewer defects and a stronger emission [10]. Figure 3 shows the typical XRD patterns of the bare $\mathrm{SrAl}_{2} \mathrm{O}_{4}: \mathrm{Eu}^{2+}, \mathrm{Dy}^{3+}$ (without $\mathrm{Li}^{+}$) and $\mathrm{SrAl}_{2} \mathrm{O}_{4}: \mathrm{Eu}^{2+}$, $\mathrm{Dy}^{3+}, \mathrm{Li}^{+}$(codoped with $0.03 \mathrm{~mol} \%$, optimum codoping concentration) samples. Both samples exhibited identical diffraction patterns, which can be indexed to the spinel structure of $\mathrm{SrAl}_{2} \mathrm{O}_{4}$ (JCPDS No. 34-379). Obviously, the XRD peaks of the $\mathrm{SrAl}_{2} \mathrm{O}_{4}: \mathrm{Eu}^{2+}, \mathrm{Dy}^{3+}, \mathrm{Li}^{+}$were sharper and stronger than those of bare $\mathrm{SrAl}_{2} \mathrm{O}_{4}: \mathrm{Eu}^{2+}, \mathrm{Dy}^{3+}$ (without $\mathrm{Li}^{+}$), suggesting their better crystallinity. The calculated mean crystallite sizes of the samples (based on Debye-Scherrer's equation) were equal to $48 \pm 1.3 \mathrm{~nm}$ and $64 \pm 1.7 \mathrm{~nm}$ for bare $\mathrm{SrAl}_{2} \mathrm{O}_{4}: \mathrm{Eu}^{2+}, \mathrm{Dy}^{3+}$ (without $\mathrm{Li}^{+}$) and $\mathrm{SrAl}_{2} \mathrm{O}_{4}: \mathrm{Eu}^{2+}$, $\mathrm{Dy}^{3+}, \mathrm{Li}^{+}$powders, respectively. This shows that the crystallinity of the $\mathrm{SrAl}_{2} \mathrm{O}_{4}: \mathrm{Eu}^{2+}, \mathrm{Dy}^{3+}, \mathrm{Li}^{+}$was improved with the addition of $\mathrm{Li}^{+}$ions. Therefore, the incorporation of $\mathrm{Li}^{+}$ions does not alter the emission peak positions but improves the emission intensity thanks to the improved crystallinity and distortion of the local symmetry in the host matrix.

Figure 4 shows comparative decay curves of the bare $\mathrm{SrAl}_{2} \mathrm{O}_{4}: \mathrm{Eu}^{2+}, \mathrm{Dy}^{3+}$ and $\mathrm{SrAl}_{2} \mathrm{O}_{4}: \mathrm{Eu}^{2+}, \mathrm{Dy}^{3+} / 0.03 \mathrm{~mol} \% \mathrm{Li}^{+}$. The results indicate that the decay process of the two kinds of phosphors contains both rapid and slow decay processes. It is clear from the figure that $\mathrm{SrAl}_{2} \mathrm{O}_{4}: \mathrm{Eu}^{2+}, \mathrm{Dy}^{3+} / 3 \mathrm{~mol} \% \mathrm{Li}^{+}$ sample displays a higher intensity and longer afterglow time than the bare $\mathrm{SrAl}_{2} \mathrm{O}_{4}: \mathrm{Eu}^{2+}, \mathrm{Dy}^{3+}$; the initial luminescence brightness was improved from 1.89 candela $\mathrm{cd} / \mathrm{m}^{2}$ to 2.71 $\mathrm{cd} / \mathrm{m}^{2}$ and the long afterglow time was prolonged from 103 to $121 \mathrm{~min}$. Thus, the introduction of $\mathrm{Li}^{+}$enhances the initial 


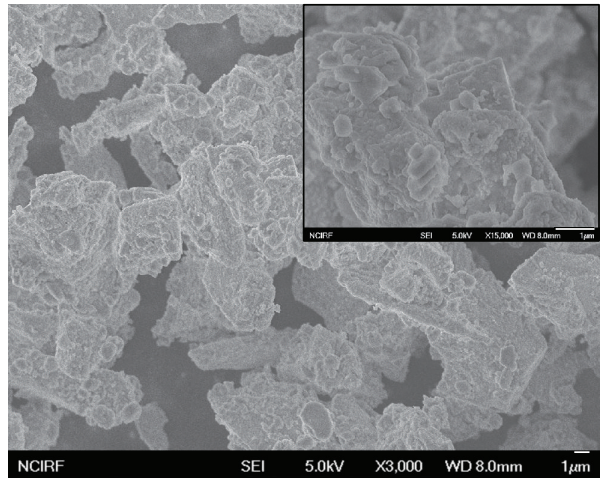

(a)

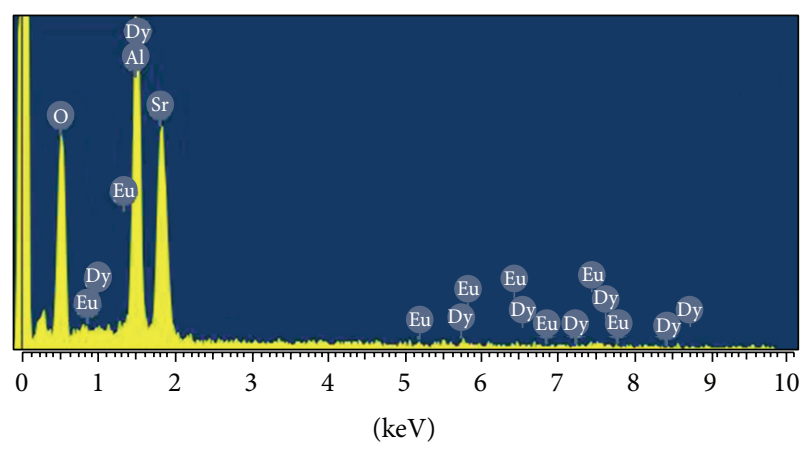

Full scale 378 cts cursor: $0.000 \mathrm{keV}$

FIGURE 1: FESEM micrographs (a) and EDX spectra (b) of $\mathrm{SrAl}_{2} \mathrm{O}_{4}: \mathrm{Eu}^{2+}, \mathrm{Dy}^{3+}$ powder.

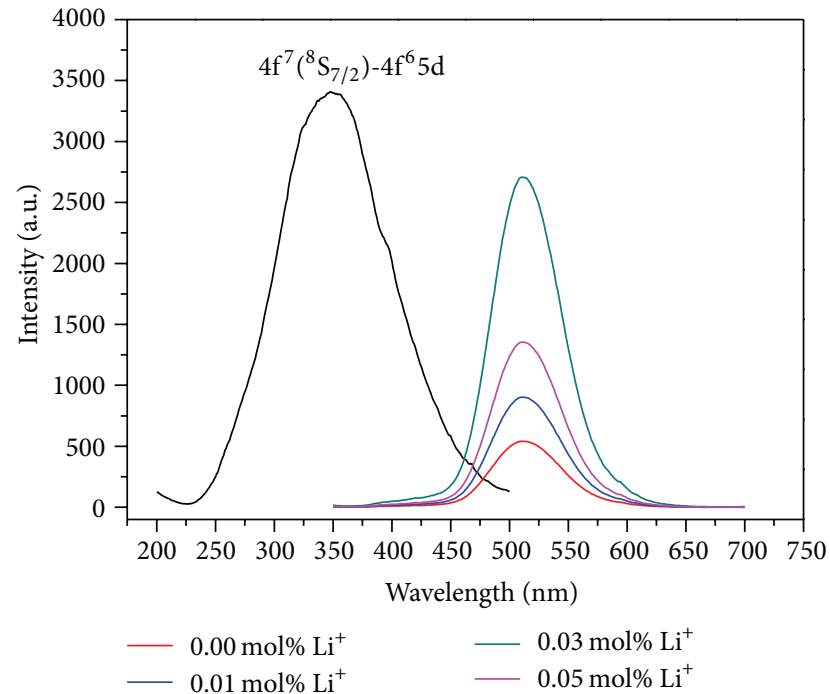

FIGURE 2: Normalized PL excitation and emission spectra of the samples as a function of $\mathrm{Li}^{+}$content.

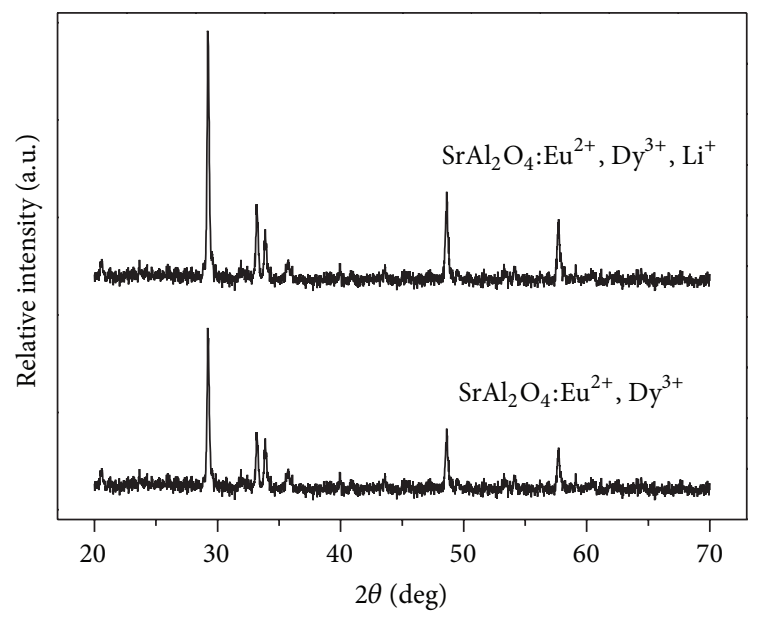

FIGURE 3: Typical XRD patterns of the bare $\mathrm{SrAl}_{2} \mathrm{O}_{4}: \mathrm{Eu}^{2+}, \mathrm{Dy}^{3+}$ and $\mathrm{SrAl}_{2} \mathrm{O}_{4}: \mathrm{Eu}^{2+}, \mathrm{Dy}^{3+} / 0.03 \mathrm{~mol} \% \mathrm{Li}^{+}$.

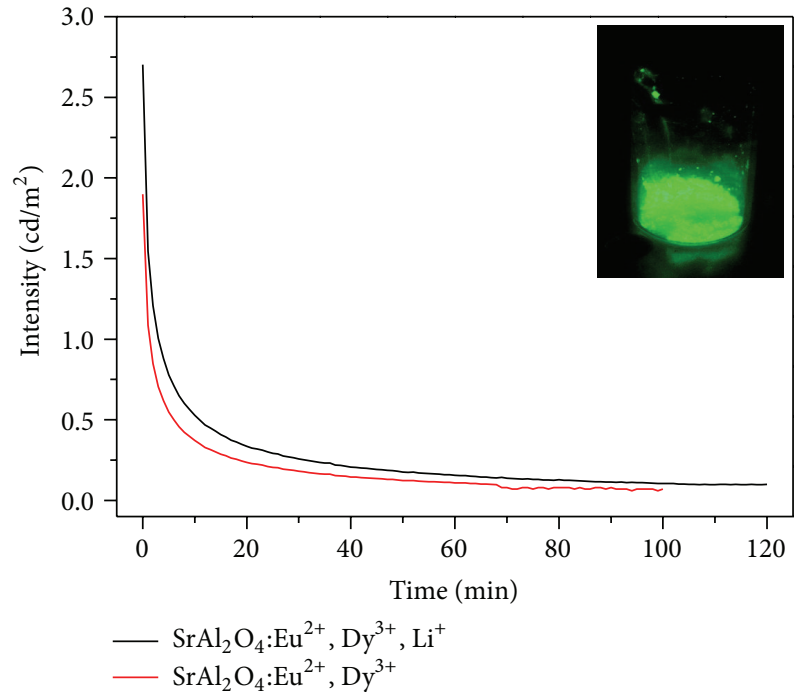

Figure 4: Decay curves of the bare $\mathrm{SrAl}_{2} \mathrm{O}_{4}: \mathrm{Eu}^{2+}, \mathrm{Dy}^{3+}$ and $\mathrm{SrAl}_{2} \mathrm{O}_{4}: \mathrm{Eu}^{2+}, \mathrm{Dy}^{3+} / 0.03 \mathrm{~mol} \% \mathrm{Li}^{+}$powders. Inset is digital photography of excited phosphorescent $\mathrm{SrAl}_{2} \mathrm{O}_{4}: \mathrm{Eu}^{2+}, \mathrm{Dy}^{3+} / 0.03 \mathrm{~mol} \%$ $\mathrm{Li}^{+}$powder.

brightness and extends the afterglow time in $\mathrm{SrAl}_{2} \mathrm{O}_{4}: \mathrm{Eu}^{2+}$, $\mathrm{Dy}^{3+}$. The addition of $\mathrm{Li}^{+}$probably increases the number of oxygen vacancies, which might act as a sensitizer for the energy transfer to rare-earth ions due to the strong mixing of charge transfer states resulting in the highly enhanced emission intensity [10]. However, the phosphorescence quenching also occurs at higher doping content of $\mathrm{Li}^{+}$due to the excess oxygen vacancies at the host, which destroy the crystallinity of the host material [11].

\section{Conclusions}

In conclusion, $\mathrm{Li}^{+}$-modified $\mathrm{SrAl}_{2} \mathrm{O}_{4}: \mathrm{Eu}^{2+}, \mathrm{Dy}^{3+}$ ceramic powders were fabricated by combustion synthesis method. The crystal structure and morphology of the synthesized powders were characterized by XRD, FESEM, and EDX. 
The PL spectroscopy was used to examine the phosphorescent properties of synthesized powders. The $\mathrm{Li}^{+}$concentration dependence on the phosphorescent properties of those powders was also examined. The enhancement of emission intensity was attributed with a distortion of the local crystal field in the host matrix combined with a better crystallinity effect of final powder composites. The initial brightness and afterglow properties of $\mathrm{Li}^{+}$-modified $\mathrm{SrAl}_{2} \mathrm{O}_{4}: \mathrm{Eu}^{2+}, \mathrm{Dy}^{3+}$ ceramic powders were enhanced by the introduction of $\mathrm{Li}^{+}$ into the $\mathrm{SrAl}_{2} \mathrm{O}_{4}: \mathrm{Eu}^{2+}, \mathrm{Dy}^{3+}$ matrix.

\section{Conflict of Interests}

The authors declare that there is no conflict of interests regarding the publication of this paper.

\section{Acknowledgment}

This work was supported by the National Research Foundation of Korea (Grant no. 2012R1A1B3001357).

\section{References}

[1] A. N. Yerpude and S. J. Dhoble, "Combustion synthesis of blueemitting submicron $\mathrm{CaAl}_{4} \mathrm{O}_{7}: \mathrm{Eu}^{2+}, \mathrm{Dy}^{3+}$ persistence phosphor," Luminescence, vol. 27, no. 6, pp. 450-454, 2012.

[2] A. S. Maia, R. Stefani, C. A. Kodaira, M. C. F. C. Felinto, E. E. S. Teotonio, and H. F. Brito, "Luminescent nanoparticles of $\mathrm{MgAl}_{2} \mathrm{O}_{4}: \mathrm{Eu}$, Dy prepared by citrate sol-gel method," Optical Materials, vol. 31, no. 2, pp. 440-444, 2008.

[3] B. Cheng, Z. Znang, Z. Han, Y. Xiao, and S. Lei, " $\mathrm{SrAl}_{2} \mathrm{O}_{4}: \mathrm{Eu}^{2+}, \mathrm{Dy}^{3+}$ nanobelts: synthesis by combustion and properties of long-persistent phosphorescence," Journal of Materials Research, vol. 26, pp. 2311-2315, 2011.

[4] G. Blasse and B. C. Grabmaier, Luminescent Materials, Springer, Berlin, Germany, 1994.

[5] W. He, T. S. Atabaev, H. K. Kim, and Y. H. Hwang, "Enhanced sunlight harvesting of dye-sensitized solar cells assisted with long persistent phosphor materials," The Journal of Physical Chemistry C, vol. 117, no. 35, pp. 17894-17900, 2013.

[6] T. S. Atabaev, Z. Piao, Y. H. Hwang, H. K. Kim, and N. H. Hong, "Bifunctional $\mathrm{Gd}_{2} \mathrm{O}_{3}: \mathrm{Er}^{3+}$ particles with enhanced visible upconversion luminescence," Journal of Alloys and Compounds, vol. 572, pp. 113-117, 2013.

[7] S. H. Shin, J. H. Kang, D. Y. Jeon, and D. S. Zang, "Enhancement of cathodoluminescence intensities of $\mathrm{Y}_{2} \mathrm{O}_{3}$ : Eu and $\mathrm{Gd}_{2} \mathrm{O}_{3}$ : Eu phosphors by incorporation of Li ions," Journal of Luminescence, vol. 114, no. 3-4, pp. 275-280, 2005.

[8] G. Rajan and K. G. Gopchandran, "Effect of substrates on the photoemission properties of $\mathrm{Li}$ doped $\mathrm{Gd}_{2} \mathrm{O}_{3}: \mathrm{Eu}^{3+}$ nanocrystalline films," Optical Materials, vol. 33, no. 3, pp. 494-500, 2011.

[9] T. S. Atabaev, H. H. T. Vu, Z. Piao, Y. H. Hwang, and H. K. Kim, "Tailoring the luminescent properties of $\mathrm{Gd}_{2} \mathrm{O}_{3}: \mathrm{Tb}^{3+}$ phosphor particles by codoping with $\mathrm{Al}^{3+}$ ions," Journal of Alloys and Compounds, vol. 541, pp. 263-268, 2012.

[10] Q. Du, G. Zhou, J. Zhou, X. Jia, and H. Zhou, "Enhanced luminescence of novel $\mathrm{Y}_{2} \mathrm{Zr}_{2} \mathrm{O}_{7}: \mathrm{Dy}^{3+}$ phosphors by $\mathrm{Li}^{+}$codoping," Journal of Alloys and Compounds, vol. 552, pp. 152-156, 2013.
[11] L. Li, H. K. Yang, B. K. Moon et al., "Photoluminescence properties of $\mathrm{CeO}_{2}: \mathrm{Eu}^{3+}$ nanoparticles synthesized by a sol-gel method," The Journal of Physical Chemistry C, vol. 113, pp. 610617, 2009. 

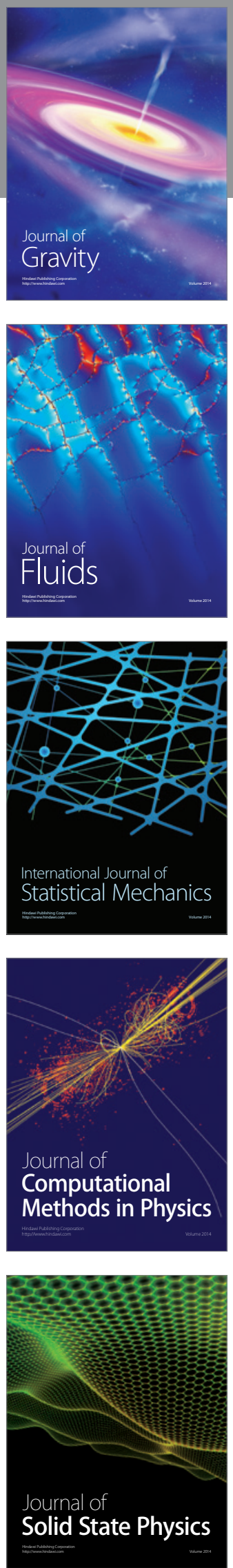

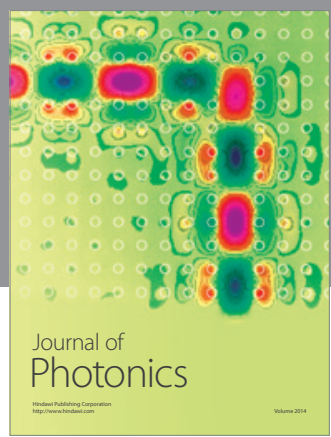

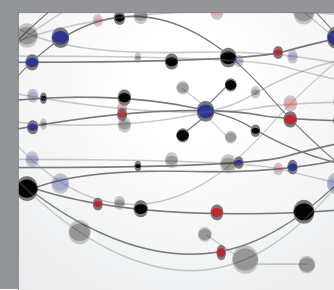

The Scientific World Journal

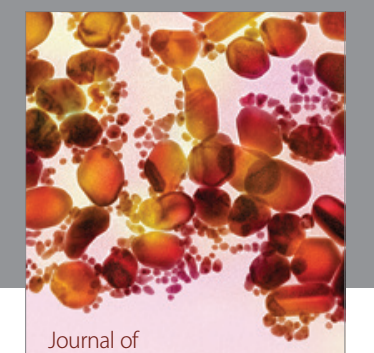

Soft Matter
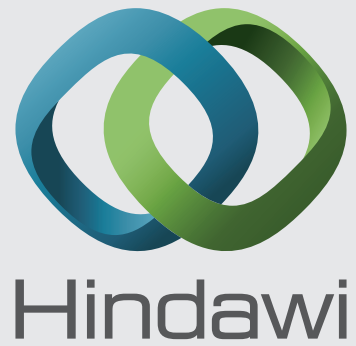

Submit your manuscripts at

http://www.hindawi.com
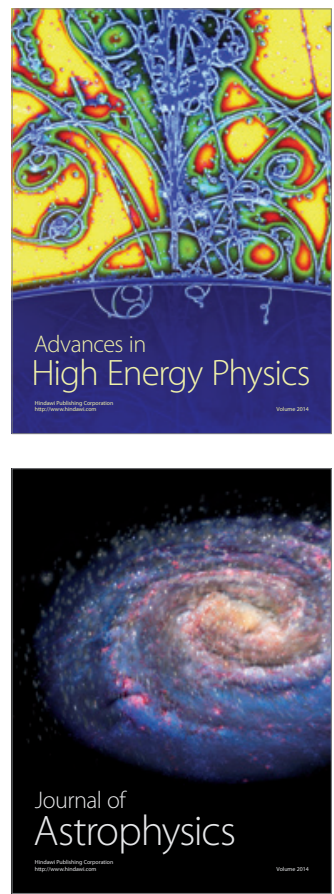
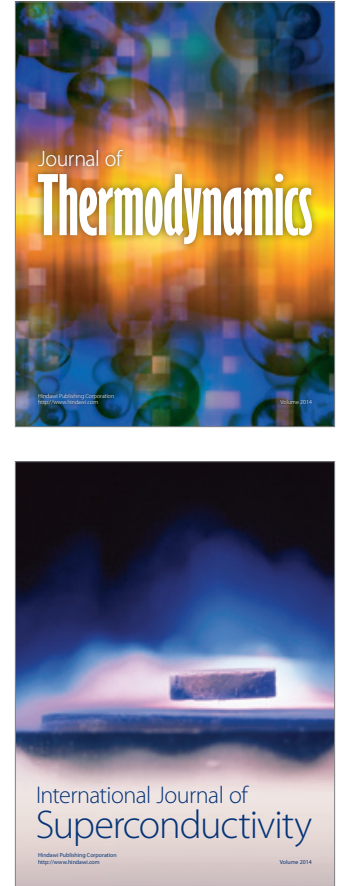
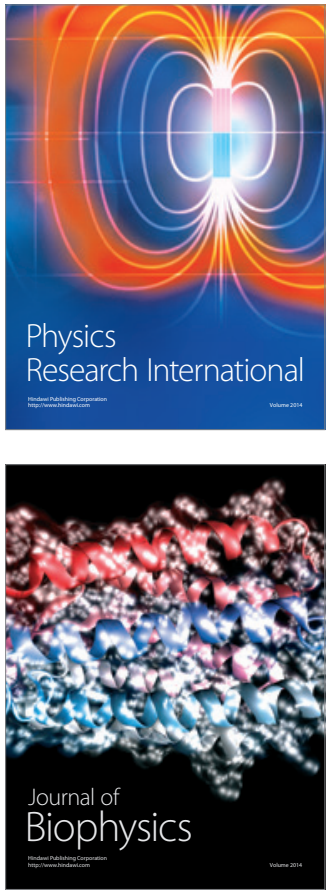
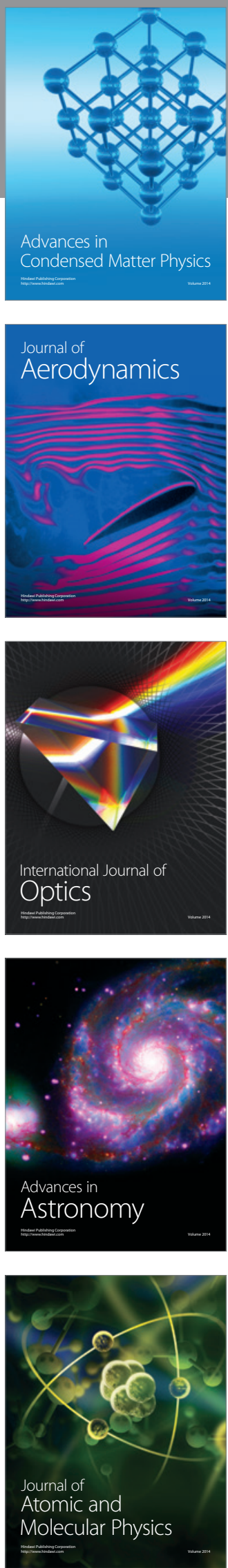